\title{
Fasting increases shelter use in house crickets (Acheta domesticus)
}

\author{
L.E. Vossen ${ }^{1 *}$ iD, E. Roman ${ }^{1,2}$ iD and A. Jansson ${ }^{1}$ iD \\ ${ }^{1}$ Department of Anatomy, Physiology and Biochemistry, Swedish University of Agricultural Sciences, Box 7011, 750 07 \\ Uppsala, Sweden; ${ }^{2}$ Department of Pharmaceutical Biosciences, Uppsala University, Box 591, 751 24 Uppsala, Sweden; \\ laura.vossen@slu.se
}

Received: 16 March 2021 / Accepted: 22 April 2021

(c) 2021 Wageningen Academic Publishers

\section{OPEN ACCESS (c) (i) SHORT COMMUNICATION}

\begin{abstract}
Fasting, i.e. depriving the animals of food prior to harvesting, has been practised in the production of house crickets (Acheta domesticus). However, the effectiveness of this method in reducing microbial loads is still unclear. In addition, there may be costs of fasting to the organism, which could compromise product quality and animal welfare. Here, we analysed spontaneous behaviour displayed after 0, 24 or 48 hours of fasting. We show that after 48 hours of fasting, shelter use was increased and the duration spent on the exposed area of the floor was decreased. The same trend was seen after 24 hours fasting. Moreover, in both fasting treatments, a strong reduction in grooming was seen. We conclude that, in the absence of a microbial lowering effect of fasting and considering the current finding that fasting induces behavioural responses in crickets, there is currently no scientific support for using fasting in cricket production.
\end{abstract}

Keywords: insect production, starvation, behaviour

\section{Introduction}

In house crickets (Acheta domesticus), the gut contains high microbial loads as well as a high diversity of bacterial communities, including spore-forming species (FernandezCassi et al., 2020; Klunder et al., 2012; Vandeweyer et al., 2017). Some insect production facilities apply a 24 to 48 hour fasting period prior to harvesting to reduce the gut content. However, we recently discovered that total aerobic counts (TAC) were increased rather than decreased in crickets fasted for 48 hours (Inácio et al., in press). Also in mealworm larvae (Tenebrio molitor), a 48 hour starvation did not bring about a shift in the composition of the microbial community (Wynants et al., 2017). Hence, fasting does not seem to have the intended effect on insect gut microbiota. In addition, there may be a cost of fasting to the organism, which could compromise product quality and animal welfare.

Insects show similar metabolic responses to fasting as vertebrates, i.e. a three-stage paradigm of fuel shifting (Belkhou et al., 1991). After an initial reliance on carbohydrates in the haemolymph (stage I), a longer steady- state is reached where lipids are the predominant source of energy (stage II). During the third stage, lipid oxidation decreases and protein oxidation progressively increases. Indeed lipids provide the most important fuel for fasting animals and starvation resistance is often positively correlated with lipid content both between individuals (Hoffmann and Harshman, 1999) and between species (Djawdan et al., 1998).

Using diets enriched with stable isotopes $\left({ }^{13} \mathrm{C}\right.$-palmitic acid or ${ }^{13} \mathrm{C}$-leucine as a marker for lipid resp. protein oxidation), McCue et al. (2015) reported that in adult house crickets, lipid oxidation is increased as early as 24 hours post feeding (earlier could not be quantified in this design) and from 60 hours, protein oxidation increases. This suggests that both at 24 and 48 hours post feeding, house crickets have not reached the tissue damaging stage of protein catabolism. Nevertheless other starvation responses may have set in. For example, in Drosophila melanogaster, genes involved in immune response and reproduction become downregulated already 24 hours post feeding while $50 \%$ of the flies survive for at least 60 hours (Fujikawa et al., 2009). 
Even if fasting would not affect the physical health of the animal, it may still negatively influence animal welfare if the animal 'wants something it does not have' (Dawkins, 2004). Animals may be highly motivated to obtain food and can become restless, try to find food or attempt to escape if they are deprived of food. Freedom from thirst, hunger or malnutrition is, after all, the first of the five freedoms devised by the Farm Animal Welfare Council (FAWC, 1993). Behavioural measures provide a noninvasive, non-intrusive way of assessing animal welfare and shed light on the choices and preferences of animals (Dawkins, 2004).

Here, we assess whether fasting for 24 or 48 hours alters the behaviour of house crickets. We observed freely occurring behaviours in adult male-female pairs with access to a shelter and drinking water. This is a first attempt to evaluate the consequences of fasting for insect welfare.

\section{Materials and methods}

\section{Animals and housing}

The adult house crickets used in this experiment were from our outbred laboratory population established from and regularly backcrossed with wild-caught individuals collected in Sweden (Vaga et al., 2020). The animals were reared in plastic boxes in groups of 5-50 individuals on a standard wheat- and oat-based pellet feed (Vaga et al., 2020) in a climate controlled room at $30 \pm 1{ }^{\circ} \mathrm{C}, 45-50 \%$ relative humidity and a 12 hour light/dark cycle with light on at 07:00 CET. During rearing, animals had ad libitum access to feed, tap water for drinking (in $10 \mathrm{ml}$ cotton-plugged tubes) and a shelter known to be preferred by house crickets (Vaga et al., 2018; black plastic tubes, $6 \times \varnothing 2.5$ with plastic straws $\varnothing 0.5$ or $0.8 \mathrm{~cm})$.

\section{Experimental treatment}

The experiment was carried out in December 2019 and February 2020 at the Swedish University of Agricultural Sciences (SLU) in Uppsala, Sweden. At the start of the experiment, animals were randomly assigned to one of three treatments: 'control' (24 hours in experimental boxes with ad libitum access to standard feed and water), '24h' or '48h' (24 resp. 48 hours in experimental boxes without feed but with ad libitum access to water). Sixteen male and sixteen female crickets were used per treatment (total of 96 crickets). Crickets were placed in male/female pairs (one pair is one replicate) in transparent experimental plastic boxes $(12 \times 12 \times 6 \mathrm{~cm}$ or $20 \times 17 \times 14 \mathrm{~cm})$ with air holes. All the boxes contained a shelter (see previous section) and a tube with tap water.

\section{Behavioural scoring}

Animals were video recorded in their experimental boxes using an iPhone 8 (Apple, Cupertino, U.S.A.) at experimental time 24:00 - 25:00 hours (control and 24h treatment) or 48:00 - 49:00 hours (48h treatment), 1-3 hours into the light phase, for a duration of one minute, during six subsequent occasions (every tenth minute). Using Boris behavioural observation software (Friard and Gamba, 2016), the duration (s) of time that the animal spent hidden behind the shelter, on the shelter, inside the shelter, on the floor or on the wall was manually scored. The duration (s) spent moving included both movement of the bodies' centerpoint as well as movement of the limbs while the centerpoint kept the same location. Duration (s) grooming (cleaning the head or legs with the mouth), eating, drinking, egg laying, copulating and vocalising (male calling) were also scored. Since the individual's sex could not be distinguished in each video, the individual's behaviour in one minute could not be linked to the next. The experimenter that performed behavioural scoring (L.E.V.) did not have formal knowledge of the assigned treatment at the time of scoring, although the control group could be distinguished from the other treatments by the presence of food.

\section{Statistical analyses}

Statistical analyses were performed in $\mathrm{R}$ version 4.0.2 (R Core Team, 2020). Eating, drinking, egg laying and copulating behaviour occurred too infrequently to be analysed statistically. The remaining seven behaviours were divided by the duration that the animal was visible (i.e. not behind the shelter) to obtain proportions, which were logit transformed and analysed with seven linear mixed-effects models (LMERs) containing a fixed effect of fasting treatment and nested random effects of month, box and minute.

\section{Results}

Fasting influenced where in the arena the animals were located. Animals that were fasted for 48 hours spent more time inside the shelter than controls ( $28 \mathrm{vs} 7 \%$; least square means, $\mathrm{t}_{2,46}=-2.237, P=0.030$, Figure $1 \mathrm{~A}$ ) and less time on the floor ( 6 vs $22 \%$; least square means, $\mathrm{t}_{2,45}=2.330$, $P=0.024$, Figure 1B). A tendency for spending less time on the floor was also detected for the $24 \mathrm{~h}$ group (11 vs $22 \%$; least square means, $\mathrm{t}_{2,45}=1.649, P=0.106$, Figure $\left.1 \mathrm{~B}\right)$. No effect of fasting was detected for the duration of time spent on top of the shelter (LMER, $\mathrm{F}_{2,45}=0.314, P=0.733$ ) or on the wall (LMER, $\mathrm{F}_{2,45}=0.607, P=0.549$ ). Duration spent moving was not affected by fasting treatment (LMER, $\mathrm{F}_{2,45}=1.082, P=0.348$ ), although the 48 h group showed a trend for moving less (Figure 1C). 
A

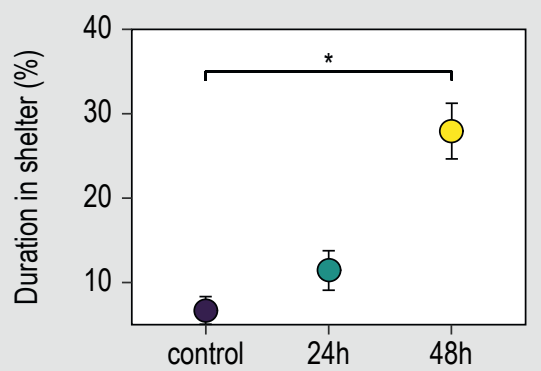

C

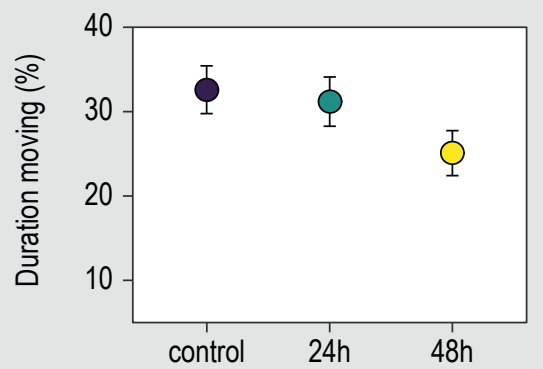

B

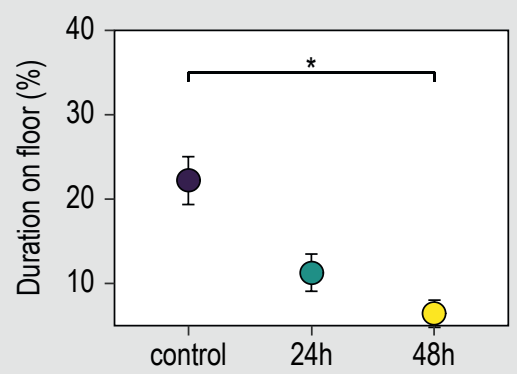

D

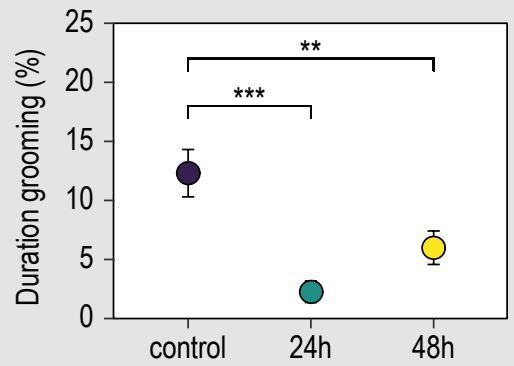

Figure 1. Effect of fasting treatment on behaviour. Duration (\%) of time spent in shelter (A), on the floor (B), moving (C) or grooming (D) in experimental groups with access to food (control), fasting for 24 hours (24h) or fasting for 48 hours (48h). Dots with error bars represent mean \pm S.E.M.

Fasting strongly reduced grooming behaviour (LMER, $\mathrm{F}_{2,45}=10.818, P<0.001$, Figure 1D) in both the $24 \mathrm{~h}$ group ( 2 vs $12 \%$; least square means, $\mathrm{t}_{2,46}=4.610, P<0.001$ ) and the 48 h group ( 6 vs $12 \%$; least square means, $\mathrm{t}_{2,44}=2.801$, $P=0.008)$. We did not detect an effect of fasting on male call duration (LMER, $\mathrm{F}_{2,45}=2.400, P=0.102$ ).

\section{Discussion}

Food availability inherently fluctuates in nature, therefore many animals possess evolved behavioural, physiological and biochemical responses to survive periods of food scarcity. In terms of behaviour, the animal must at any one point in time choose between attempting to find novel food, or conserve energy by reducing its locomotory activity. In the current experiment, we found no evidence for increased food-searching behaviour or increased activity. Rather, at 48 hours post-feeding captive house crickets increased their use of the shelter and avoided the exposed area on the floor, which could be a strategy to conserve energy (minimising heat loss via radiation and convection) and to minimise the risk of predation while doing so. Also, both fasted groups displayed less grooming which may be explained by the general reduction in activity and/or by the reduced need to clean the exoskeleton of food particles.

Shelter seeking is also seen in response to a (mock) predator (Adamo et al., 2013) and after social defeat (Rillich et al., 2011), therefore this behaviour could be indicative of an aversive situation (Dawkins, 2004). Alternatively, the shelter might be the preferred location for rest or sleep-like behaviour (Hendricks et al., 2000), in which case fasting could be a 'neutral' situation that the animals simply wait out. This distinction is relevant since insects are capable of nociception and can even learn to avoid noxious stimuli (Sneddon et al., 2014). Additional experiments are needed to evaluate how motivated fasting crickets are to obtain food, for example by letting the animal perform work in order to reach a food compartment (Olsson et al., 2002), and contrasting access to food to other resources, such as potential mates or environmental enrichment (Mason et al., 2001). Physiological measurements, such as the (neuro) hormone octopamine (Adamo et al., 1995) and adipokinetic hormone (Lee and Park, 2004) can also contribute to the assessment of whether fasting influences welfare (Dawkins, 2004). In rats, the final stage of fasting (protein oxidation) is associated with a rise in corticosterone level (Belkhou et al., 1991).

It should be noted that the effect of fasting on locomotory activity is likely dependent on the circadian rhythm. In D. melanogaster, fasting leads to an overall increase in locomotory activity (Knoppien et al., 2000), due to an elongation and intensification of the daily activity peaks at dawn and dusk (Lee and Park, 2004). However, when activity was low (during the day and middle of the night), starved flies showed both higher and lower activity compared to fed conspecifics (Lee and Park, 2004). We conducted behavioural observations during the inactive part of the day, hence it would be interesting to quantify behaviour of crickets during the entire light/dark cycle.

To conclude, in the absence of clear beneficial effects of fasting in reducing microbial loads and considering the 
current findings that fasting induces behavioural responses in crickets, some of which could be aversive, we see no need to apply this method.

\section{Acknowledgements}

This work was supported by grants from the Swedish Research Council Formas (2016-00361 to A.J.) and the Carl Tryggers Foundation (CTS 20:352 to E.R.).

\section{References}

Adamo, S., Linn, C. and Hoy, R., 1995. The role of neurohormonal octopamine during 'fight or flight' behaviour in the field cricket Gryllus bimaculatus. The Journal of Experimental Biology 198: 1691-1700.

Adamo, S.A., Kovalko, I. and Mosher, B., 2013. The behavioural effects of predator-induced stress responses in the cricket (Gryllus texensis): the upside of the stress response. The Journal of Experimental Biology 216: 4608-4614. https://doi.org/10.1242/jeb.094482

Belkhou, R., Cherel, Y., Heitz, A., Robin, J.-P. and Le Maho, Y., 1991. Energy contribution of proteins and lipids during prolonged fasting in the rat. Nutrition Research 11: 365-374.

Dawkins, M.S., 2004. Using behaviour to assess animal welfare. Animal Welfare 13: S3-7.

Djawdan, M., Chippindale, A.K., Rose, M.R. and Bradley, T.J., 1998. Metabolic reserves and evolved stress resistance in Drosophila melanogaster. Physiological Zoology 71: 584-594.

Farm Animal Welfare Council (FAWC), 1993. Report on priorities for animal welfare research and development. FAWC, London, UK, $26 \mathrm{pp}$.

Fernandez-Cassi, X., Söderqvist, K., Bakeeva, A., Vaga, M., Dicksved, J., Vagsholm, I., Jansson, A. and Boqvist, S., 2020. Microbial communities and food safety aspects of crickets (Acheta domesticus) reared under controlled conditions. Journal of Insects as Food and Feed 6: 429-440. https://doi.org/10.3920/jiff2019.0048

Friard, O. and Gamba, M., 2016. BORIS: a free, versatile open-source event-logging software for video/audio coding and live observations. Methods in Ecology and Evolution 7: 1325-1330. https://doi. org/10.1111/2041-210x.12584

Fujikawa, K., Takahashi, A., Nishimura, A., Itoh, M., Takano-Shimizu, T. and Ozaki, M., 2009. Characteristics of genes up-regulated and down-regulated after $24 \mathrm{~h}$ starvation in the head of Drosophila. Gene 446: 11-17. https://doi.org/10.1016/j.gene.2009.06.017

Hendricks, J.C., Finn, S.M., Panckeri, K.A., Chavkin, J., Williams, J.A., Sehgal, A. and Pack, A.I., 2000. Rest in Drosophila is a sleep-like state. Neuron 25: 129-138.

Hoffmann, A.A. and Harshman, L.G., 1999. Desiccation and starvation resistance in Drosophila: patterns of variation at the species, population and intrapopulation levels. Heredity 83: 637-643.

Inácio, A.C., Vågsholm, I., Jansson, A., Vaga, M., Boqvist, S. and Fraqueza, M.J., in press. Impact of starvation on fat content and microbial load in edible crickets (Acheta domesticus) Journal of Insects as Food and Feed. https://doi.org/10.3920/jiff2020.0157
Klunder, H.C., Wolkers-Rooijackers, J., Korpela, J.M. and Nout, M.J.R., 2012. Microbiological aspects of processing and storage of edible insects. Food Control 26: 628-631. https://doi.org/10.1016/j. foodcont.2012.02.013

Knoppien, P., Van der Pers, J.N.C. and Van Delden, W., 2000. Quantification of locomotion and the effect of food deprivation on locomotor activity in Drosophila. Journal of Insect Behavior 13: 27-43.

Lee, G. and Park, J.H., 2004. Hemolymph sugar homeostasis and starvation-induced hyperactivity affected by genetic manipulations of the adipokinetic hormone-encoding gene in Drosophila melanogaster. Genetics 167: 311-323.

Mason, G.J., Cooper, J. and Clarebrough, C., 2001. Frustrations of fur-farmed mink. Nature 410: 35-36.

McCue, M.D., Guzman, R.M., Passement, C.A. and Davidowitz, G., 2015. How and when do insects rely on endogenous protein and lipid resources during lethal bouts of starvation? A new application for 13C-breath testing. PLoS One 10(10): e0140053.

Olsson, I.A.S., Keeling, L.J. and McAdie, T.M., 2002. The push-door for measuring motivation in hens: an adaptation and a critical discussion of the method. Animal Welfare 11: 1-10.

R Core Team, 2020. R: a language and environment for statistical computing. R Foundation for Statistical Computing, Vienna, Austria.

Rillich, J., Schildberger, K. and Stevenson, P.A., 2011. Octopamine and occupancy: an aminergic mechanism for intruder-resident aggression in crickets. Proceedings of the Royal Society B Biological Sciences 278: 1873-1880. https://doi.org/10.1098/ rspb.2010.2099

Sneddon, L.U., Elwood, R.W., Adamo, S.A. and Leach, M.C., 2014. Defining and assessing animal pain. Animal Behaviour 97: 201-212. https://doi.org/10.1016/j.anbehav.2014.09.007

Vaga, M., Berggren, A., Pauly, T. and Jansson, A., 2020. Effect of red clover-only diets on house crickets (Acheta domesticus) growth and survival. Journal of Insects as Food and Feed 6: 179-189. https:// doi.org/10.3920/jiff2019.0038

Vaga, M., Gustafsson, E. and Jansson, A., 2018. Evaluation of reusable hiding units for rearing house crickets (Acheta domesticus). In: Book of Abstracts of the $6^{\text {th }}$ Annual Meeting of the European Federation of Animal Science. Dubrovnik, Croatia, 27-31 August 2018. EAAP Book of Abstracts, Vol. 24. Wageningen Academic Publishers, Wageningen, the Netherlands.

Vandeweyer, D., Crauwels, S., Lievens, B. and Van Campenhout, L., 2017. Microbial counts of mealworm larvae (Tenebrio molitor) and crickets (Acheta domesticus and Gryllodes sigillatus) from different rearing companies and different production batches. International Journal of Food Microbiology 242: 13-18. https://doi.org/10.1016/j. ijfoodmicro.2016.11.007

Wynants, E., Crauwels, S., Lievens, B., Luca, S., Claes, J., Borremans, A., Bruyninckx, L. and Van Campenhout, L., 2017. Effect of postharvest starvation and rinsing on the microbial numbers and the bacterial community composition of mealworm larvae (Tenebrio molitor). Innovative Food Science \& Emerging Technologies 42: 8-15. https://doi.org/10.1016/j.ifset.2017.06.004 